\title{
Elevating the productivity of sugarcane crop with sustainable way and means
}

\author{
Shriprakash Yadav* and Sonia Yadav \\ Sugarcane, Research Institute, U.P. Council of Sugarcane Research, SHAHJAHANPUR (U.P.) INDIA \\ (Email : drshriprakashyadav@gmail.com; soinaupcsr@gmail.com)
}

\begin{abstract}
In northern region as well as in India, sugarcane is a major commercial crop that sustains sugar industry, the second largest next to cotton and textiles industries. India occupies better position in the world in area and production after Brazil but the cane yield/ ha is generally lower than several other countries like Australia, Brazil etc. Uttar Pradesh ranks first in the country with regards to cane area and also in sugar production in the country. Therefore, the northern states role in improving national sugarcane productivity is obvious. Now days stagnation in crop yields and decline in the factor productivity have raised a question mark over sustainability of crop yield level reached during green revolution period. While the use of mineral fertilizer is the quickest and surest way of boosting crop production, their cost and other constraints frequently deter farmers for using them in recommended quantities and in balanced proportion. With the objective to develop crop nutrient management strategies for eco-friendly sugarcane production with sustaining soil health, a field experiment in spring season during 2014-16 were conducted at the research farm of Sugarcane Research Institute, Shahjahanpur (U.P.), India. Randomized Block Design and three replications with using test variety $\operatorname{CoS} 08279$ (mid late maturing) was used to conduct the experiment with nine treatments. Use of farm yard manure (FYM) @10t/ha as organics along with inorganic fertilizers on the basis of soil test + biofertilizers (Azotobacter +P.S.B.@10kg/ha each) had to positive effect on sugarcane growth and yield and gave significantly higher cane yield (113.10 t/ ha) than the other treatments, CCS\% in cane was not affected significantly due to different treatments, Maximum benefit cost ratio (2.66) was also obtained under the aforesaid treatment.
\end{abstract}

Key Words : Sustainable, Sugarcane, Soil health, Eco-friendly, Productivity

View Point Article : Yadav, Shriprakash and Yadav, Sonia (2018). Elevating the productivity of sugarcane crop with sustainable way and means. Internat. J. agric. Sci., 14 (1) : 123-127, DOI:10.15740/HAS/IJAS/14.1/123-127.

Article History : Received : 18.07.2017; Revised : 18.11.2017; Accepted : 01.12.2017

\footnotetext{
* Author for correspondence:
} 